Polymer Journal, Vol. 38, No. 11, pp. 1146-1151 (2006)

(C) 2006 The Society of Polymer Science, Japan

\title{
Synthesis of Electron-Donating Polymer Having Vinylogous TTF in the Main Chain
}

\author{
Shinsuke InAGI, Kensuke NAKA, ${ }^{\dagger}$ Daisuke IIDA, and Yoshiki ChuJo \\ Department of Polymer Chemistry, Graduate School of Engineering, Kyoto University, \\ Katsura, Nishikyo-ku, Kyoto 615-8510, Japan
}

(Received June 30, 2006; Accepted August 18, 2006; Published October 4, 2006)

\begin{abstract}
The electron-donating polymer containing vinylogous TTF unit in the main chain was successfully obtained by oxidative polymerization of bisdithiafulvene (bisDTF) (1). The polymer was soluble in common organic solvents such as chloroform and toluene. Structural characterization of the polymer was provided by ${ }^{1} \mathrm{H}$ and ${ }^{13} \mathrm{C}$ NMR spectroscopies. The number-average molecular weight of the polymer was estimated as 5,400 by gel permeation chromatographic analysis (chloroform, polystyrene standards). Optical and electrochemical properties of the polymer were studied by UV-vis analysis and cyclic voltammetry. Charge transfer complex of the polymer with tetracyanoquinodimethane (TCNQ) was obtained in a DMSO solution. [doi:10.1295/polymj.PJ2006068]

KEY WORDS Tetrathiafulvalene / Electron-Donating Polymer / Oxidative Polymerization / Redox Polymer / Charge Transfer /
\end{abstract}

Derivatives of tetrathiafulvalene (TTF) including dithiafulvene (DTF) act as electron donors and were used for a wide range of application such as organic conductors, ${ }^{1-3}$ molecular magnets, ${ }^{4-6}$ building blocks for supramolecular chemistry ${ }^{7,8}$ and so on. To introduce TTF derivatives into a backbone of a polymer is challenging and interesting from the viewpoint of improving the processability of the organic devices and expanding the dimension of the conductive path of the electrons. There have been several attempts to incorporate TTF derivatives into side chains, ${ }^{9-12}$ and main chains ${ }^{11-14}$ of polymers, and conjugated polymers. ${ }^{15-20}$ Some of them were found to form charge transfer complexes with electron acceptors such as 7,7,8,8-tetracyanoquinodimethane (TCNQ), which showed higher electron conductivity compared to that of the uncomplexed polymers. ${ }^{21,22}$

Vinylogous TTF-containing polymers were reported by using oxidative dimerization of DTF derivatives $^{23-27}$ even though they were not well-characterized due to low solubility of the polymeric products. We have developed the synthesis of soluble polymers containing vinylogous TTF by using oxidative dimerization reaction of bisdithiafulvenyldialkoxybenzenes. ${ }^{28,29}$ Although these polymers are not conjugated polymer, they are expected to have a switching effect of the non-conjugated to conjugated polymer backbones by treatment of the polymers with electron acceptors due to structural changes to phenylenevinylene structures in the main chain of the polymers. The introduction of vinylogous TTF into the polymer backbone is of interest because of unique properties of vinylogous TTF. For example, vinylogous TTF shows lower oxidation potentials and decreasing the difference between the two oxidation potentials compared to TTF due to the reduced coulombic repulsion in the dication species. ${ }^{30,31}$ Herein we investigated to produce novel polymers having vinylogous TTF in the main chain by oxidative polymerization. To our knowledge, there is no example of vinylogous TTF containing polymers in the main chain up to date except for insoluble product made by oxidative polymerization of tetrathiapentalene. ${ }^{19,20}$

\section{EXPERIMENTAL}

\section{Materials}

Unless stated otherwise, all reagents and chemicals were obtained from commercial sources and used without further purification. Solvents were dried and distilled under nitrogen atmosphere. 1,4-Dipropionylbenzene (3) and potassium piperidine-1-carbodithioate (10) were synthesized according to the literature. ${ }^{32,33}$

\section{Measurements}

${ }^{1} \mathrm{H}$ and ${ }^{13} \mathrm{C}$ NMR spectra were recorded on a JEOL EX-400 spectrometer. UV-vis spectra were obtained on a JASCO V-530 spectrophotometer. Gel permeation chromatography (GPC) was carried out on a TOSOH 8020 (TSK-gel $\alpha-3000$ column) with $\mathrm{CHCl}_{3}$ as an eluent after calibration with polystyrene standards. Cyclic voltammetry measurement was performed with a BAS CV-50W Electrochemical Analyzer. MALDI-TOF-MS analysis was performed on an Applied Biosystems Voyager DESTR instrument equipped with $2 \mathrm{~m}$ linear and $3 \mathrm{~m}$ reflector flight tubes

${ }^{\dagger}$ To whom correspondence should be addressed (Tel: +81-75-383-2608, Fax: +81-75-383-2607, E-mail: ken@ @hujo.synchem.kyoto-u.ac.jp). 
and a $337 \mathrm{~nm}$ nitrogen laser (pulse width $=3 \mathrm{~ns}$ ), along with a delayed extraction capability.

\section{Synthesis}

1,4-Bis(2-chloropropionyl)benzene (4). ${ }^{34}$ To a stirred solution of THF $(100 \mathrm{~mL})$ and $2.0 \mathrm{M}$ solution of lithium diisopropyl amide in heptane/THF/ethylbenzene $(12.0 \mathrm{~mL}, 24.0 \mathrm{mmol})$, a solution of 1,4-dipropionylbenzene (3) $(2.05 \mathrm{~g}, 10.8 \mathrm{mmol})$ in THF $(50 \mathrm{~mL})$ was added dropwise at $-78^{\circ} \mathrm{C}$ and the reaction mixture was stirred for $1 \mathrm{~h}$. Then the temperature of the mixture was allowed to rise at room temperature. A solution of $p$-toluenesulfonyl chloride $(4.51 \mathrm{~g}, 23.7$ $\mathrm{mmol})$ in THF $(50 \mathrm{~mL})$ was added slowly to the reaction mixture at room temperature and the reaction mixture was stirred for $18 \mathrm{~h}$. To the mixture was added water and extracted two times with $\mathrm{Et}_{2} \mathrm{O}$. The extracts were washed with water and dried over $\mathrm{MgSO}_{4}$. The filtrate was evaporated and the crude product was purified by column chromatography on a silica gel with hexane $/ \mathrm{CHCl}_{3}(2 / 1)$ as an eluent to give a white powder. (204 mg, $0.80 \mathrm{mmol}$, yield 7.4\%): ${ }^{1} \mathrm{H}$ NMR $\left(\mathrm{CDCl}_{3}, \mathrm{ppm}\right) \delta 8.12(\mathrm{~s}, 4 \mathrm{H}, \operatorname{Ar}-H), 5.23(\mathrm{q}, 2 \mathrm{H}$, $\mathrm{CHCl}), 1.77$ (d, 6H, $\left.\mathrm{CH}_{3}\right) ;{ }^{13} \mathrm{C} \mathrm{NMR}\left(\mathrm{CDCl}_{3}, \mathrm{ppm}\right)$ $\delta$ 192.8, 137.7, 129.2, 52.8, 19.7.

5. To a stirred solution of $4(204 \mathrm{mg}, 0.80 \mathrm{mmol})$ in THF $(40 \mathrm{~mL})$, potassium piperidine-1-carbodithioate $(\mathbf{1 0})(438 \mathrm{mg}, 2.20 \mathrm{mmol})$ was added and the reaction mixture was refluxed for $5 \mathrm{~h}$. After the removal of the solvent, the residue was solved in $50 \mathrm{~mL}$ of $\mathrm{CHCl}_{3}$ and washed with water. Yellow solid was obtained after evaporation $(285 \mathrm{mg}, 0.56 \mathrm{mmol}$, yield $70 \%)$ and used for the following reaction without further purification: ${ }^{1} \mathrm{H}$ NMR $\left(\mathrm{CDCl}_{3}, \mathrm{ppm}\right) \delta 8.17(\mathrm{~s}, 4 \mathrm{H}, \mathrm{Ar}-H)$, 5.92 (q, 2H, $\left.\mathrm{CH}\left(\mathrm{CH}_{3}\right) \mathrm{S}\right), 3.89$ (t, $\left.8 \mathrm{H}, \mathrm{NCH}_{2} \mathrm{CH}_{2}\right), 1.73$ (s, $\left.6 \mathrm{H}, \mathrm{CH}_{3}\right), 1.64(\mathrm{~m}, 12 \mathrm{H}$, piperidine).

6. $5(285 \mathrm{mg}, 0.56 \mathrm{mmol})$ was cooled in an ice bath. Ten $\mathrm{mL}$ of concentrated sulfuric acid were slowly added and the solution was stirred for $5 \mathrm{~h}$ at $0{ }^{\circ} \mathrm{C}$. Distilled water $(50 \mathrm{~mL})$ and hexafluorophospholic acid $(60 \mathrm{wt} \%, 0.30 \mathrm{~mL})$ were added to the reaction mixture and kept for $30 \mathrm{~min}$ at $0{ }^{\circ} \mathrm{C}$. White precipitate was filtered and washed with water and ether $(326 \mathrm{mg}$, $0.43 \mathrm{mmol}$, yield $76 \%$ ): ${ }^{1} \mathrm{H}$ NMR (DMSO- $d_{6}, \mathrm{ppm}$ ) $\delta 7.74(\mathrm{~s}, 4 \mathrm{H}, \mathrm{Ar}-\mathrm{H}), 3.84$ (t, $\left.8 \mathrm{H}, \mathrm{NCH}_{2} \mathrm{CH}_{2}\right), 2.44$ (s, 6H, $\left.\mathrm{CH}_{3}\right), 1.83$ (s, $\left.8 \mathrm{H}, \mathrm{NCH}_{2} \mathrm{CH}_{2}\right), 1.69$ (s, $4 \mathrm{H}$, $\mathrm{N} \mathrm{CH}_{2} \mathrm{CH}_{2} \mathrm{CH}_{2}$ ).

7. To a stirred solution of 6 ( $326 \mathrm{mg}, 0.43 \mathrm{mmol})$ in ethanol $(20 \mathrm{~mL})$ was added $\mathrm{NaBH}_{4}(50 \mathrm{mg}, 1.32$ $\mathrm{mmol})$ at $0{ }^{\circ} \mathrm{C}$. The mixture was allowed to rise at room temperature and the reaction mixture was stirred for $2 \mathrm{~h}$. After the removal of the solvent, the residue was solved in $50 \mathrm{~mL}$ of $\mathrm{CHCl}_{3}$ and washed with water. The organic phase was dried over $\mathrm{MgSO}_{4}$ and evaporated. Yellow oil was obtained $(225 \mathrm{mg}, 0.43$ mmol, yield 100\%): ${ }^{1} \mathrm{H}$ NMR $\left(\mathrm{CDCl}_{3}, \mathrm{ppm}\right) \delta 7.35$ (s, 4H, Ar- $H), 5.92\left(\mathrm{~s}, 2 \mathrm{H}, \mathrm{SCH}\left(\mathrm{NC}_{5} \mathrm{H}_{10}\right) \mathrm{S}\right), 2.63$ (t, $\left.8 \mathrm{H}, \mathrm{NCH}_{2} \mathrm{CH}_{2}\right), 2.07\left(\mathrm{~s}, 6 \mathrm{H}, \mathrm{CH}_{3}\right), 1.60(\mathrm{~m}, 8 \mathrm{H}$, $\left.\mathrm{NCH}_{2} \mathrm{CH}_{2}\right), 1.47\left(\mathrm{~m}, 4 \mathrm{H}, \mathrm{N} \mathrm{CH} \mathrm{CH}_{2} \mathrm{CH}_{2}\right)$.

8. $7(225 \mathrm{mg}, 043 \mathrm{mmol})$ was solved in ether $(10 \mathrm{~mL})$ at $0{ }^{\circ} \mathrm{C}$. Hexafluorophosphoric acid $(60 \mathrm{wt} \%$, $0.20 \mathrm{~mL}$ ) was added to the solution and the reaction mixture was stirred for $2 \mathrm{~h}$ at $0{ }^{\circ} \mathrm{C}$. The brown precipitate was filtered and washed with ether $(254 \mathrm{mg}$, $0.42 \mathrm{mmol}$, yield 97\%): ${ }^{1} \mathrm{H}$ NMR (DMSO- $d_{6}, \mathrm{ppm}$ ) $\delta 7.41$ (s, 4H, Ar- $H$ ), 6.54 (s, 2H, SCHS), 2.08 (s, 6H, $\left.\mathrm{CH}_{3}\right)$.

9. To a stirred solution of $\mathbf{8}(254 \mathrm{mg}, 0.42 \mathrm{mmol})$ in acetonitrile $(20 \mathrm{~mL}), \mathrm{NaI}(0.15 \mathrm{~g}, 1.00 \mathrm{mmol})$ and triethyl phosphite $(0.20 \mathrm{~mL})$ was added and the mixture was stirred for $1 \mathrm{~h}$ at room temperature. After evaporation of the solvent and filtration of $\mathrm{NaPF}_{6}$, precipitated by addition of $\mathrm{CHCl}_{3}$, the obtained filtrate was evaporated. The red oily product was obtained (245 mg, $0.42 \mathrm{mmol}$, yield $100 \%):{ }^{1} \mathrm{H} \mathrm{NMR}\left(\mathrm{CDCl}_{3}\right.$, ppm) $\delta 7.31(\mathrm{~s}, 4 \mathrm{H}, \mathrm{Ar}-H), 4.80(\mathrm{~s}, 2 \mathrm{H}, \mathrm{SCH}(\mathrm{PO}-$ $\left.\left.(\mathrm{OEt})_{2}\right) \mathrm{S}\right), 4.28\left(\mathrm{q}, 8 \mathrm{H}, \mathrm{OCH}_{2} \mathrm{CH}_{3}\right), 1.95\left(\mathrm{~s}, 6 \mathrm{H}, \mathrm{CH}_{3}\right)$, 1.37 (t, $\left.12 \mathrm{H}, \mathrm{OCH}_{2} \mathrm{CH}_{3}\right)$.

1. To a stirred solution of $9(245 \mathrm{mg}, 0.42 \mathrm{mmol})$ in THF $(20 \mathrm{~mL}), 1.53 \mathrm{M} n$-BuLi (diethyl ether solution, $0.8 \mathrm{~mL}, 1.2 \mathrm{mmol}$ ) was added and the reaction mixture was stirred for $30 \mathrm{~min}$ at $-78^{\circ} \mathrm{C}$. 4- $n$-Hexyloxybenzaldehyde $(260 \mathrm{mg}, 1.26 \mathrm{mmol}$ ) was added to the mixture and the stirring was maintained for $1 \mathrm{~h}$ at $-78^{\circ} \mathrm{C}$, and then $20 \mathrm{~h}$ at room temperature. After extraction with $\mathrm{CHCl}_{3}$, the organic phase was dried over $\mathrm{MgSO}_{4}$. The filtrate was evaporated and the crude product was purified by column chromatography on a silica gel with hexane/ $\mathrm{CHCl}_{3}(1 / 1)$ as an eluent to give a yellow powder. (121 mg, $0.176 \mathrm{mmol}$, yield $42 \%):{ }^{1} \mathrm{H}$ NMR $\left(\mathrm{CDCl}_{3}, \mathrm{ppm}\right) \delta 8.37(\mathrm{~s}, 4 \mathrm{H}$, Ar- $H$ ), 7.18 (m, 4H, Ar- $H$ ), 6.89 (m, 4H, Ar-H), 6.41 (s, $2 \mathrm{H}$, benzilydene protons), $3.96\left(\mathrm{t}, 4 \mathrm{H}, \mathrm{OCH}_{2}\right)$, $2.06\left(\mathrm{~s}, 6 \mathrm{H}, \mathrm{CH}_{3}\right), 1.78\left(\mathrm{~m}, 4 \mathrm{H}, \mathrm{OCH}_{2} \mathrm{CH}_{2}\right), 1.46(\mathrm{~m}$, $\left.4 \mathrm{H}, \mathrm{OCH}_{2} \mathrm{CH}_{2} \mathrm{CH}_{2}\right), 1.34\left(\mathrm{~m}, 8 \mathrm{H}, \mathrm{OC}_{3} \mathrm{H}_{6} \mathrm{C}_{2} \mathrm{H}_{4}\right), 0.91$ $\left(\mathrm{t}, 6 \mathrm{H}, \quad \mathrm{OC}_{5} \mathrm{H}_{10} \mathrm{CH}_{3}\right) ;{ }^{13} \mathrm{C} \mathrm{NMR}\left(\mathrm{CDCl}_{3}, \mathrm{ppm}\right) \delta$ 156.9, 132.5, 132.0, 129.7, 129.1, 127.8, 125.0, 123.8, 114.5, 112.1, 68.0, 31.6, 29.3, 25.7, 22.6, 14.5, 14.1; Anal. Calcd for $\mathrm{C}_{40} \mathrm{H}_{46} \mathrm{O}_{2} \mathrm{~S}_{4}$ : C, 69.93; H, 6.75; O, 4.66; S, 18.67. Found: C, 69.91; H, 6.83; O, 4.71; S, 18.54 .

\section{Polymerization}

Typical oxidative polymerization by iodine is as follows. To a stirred solution of $\mathbf{1}(57 \mathrm{mg}, 0.083$ $\mathrm{mmol})$ in toluene $(10 \mathrm{~mL})$, excess iodine $(210 \mathrm{mg}$, $0.83 \mathrm{mmol}$ ) was added and the reaction mixture was stirred for $48 \mathrm{~h}$ at room temperature. The chemical reduction was carried out by addition of an aqueous solution of sodium hydrogen sulfite $(1.12 \mathrm{~g})$ to the 


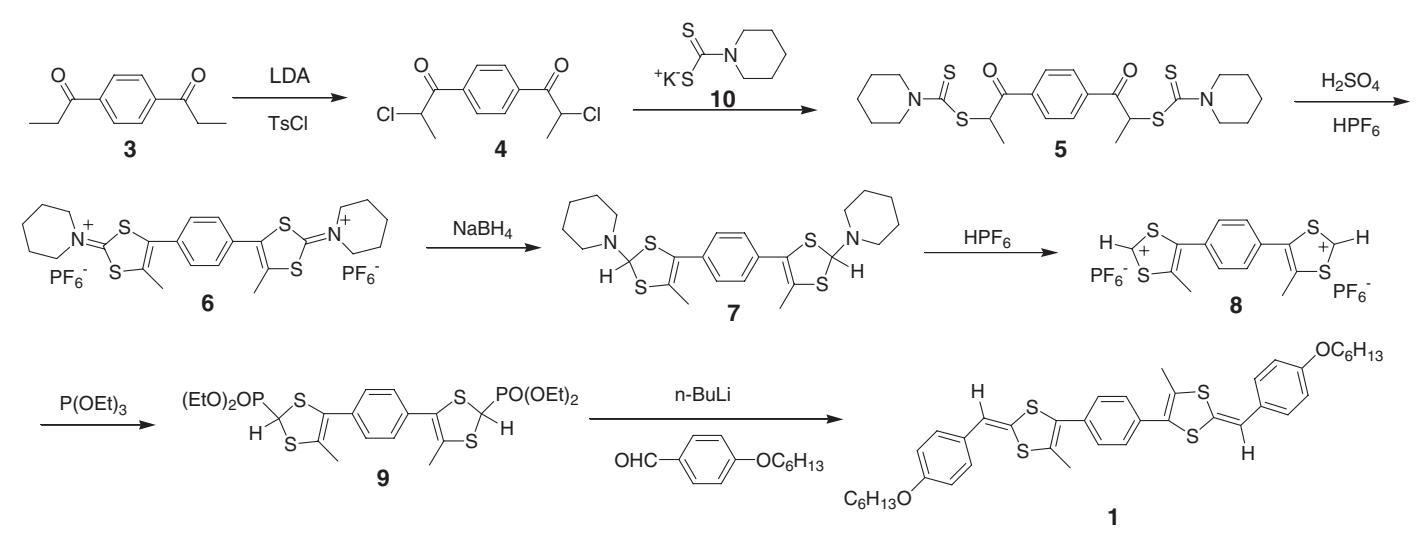

Scheme 1.

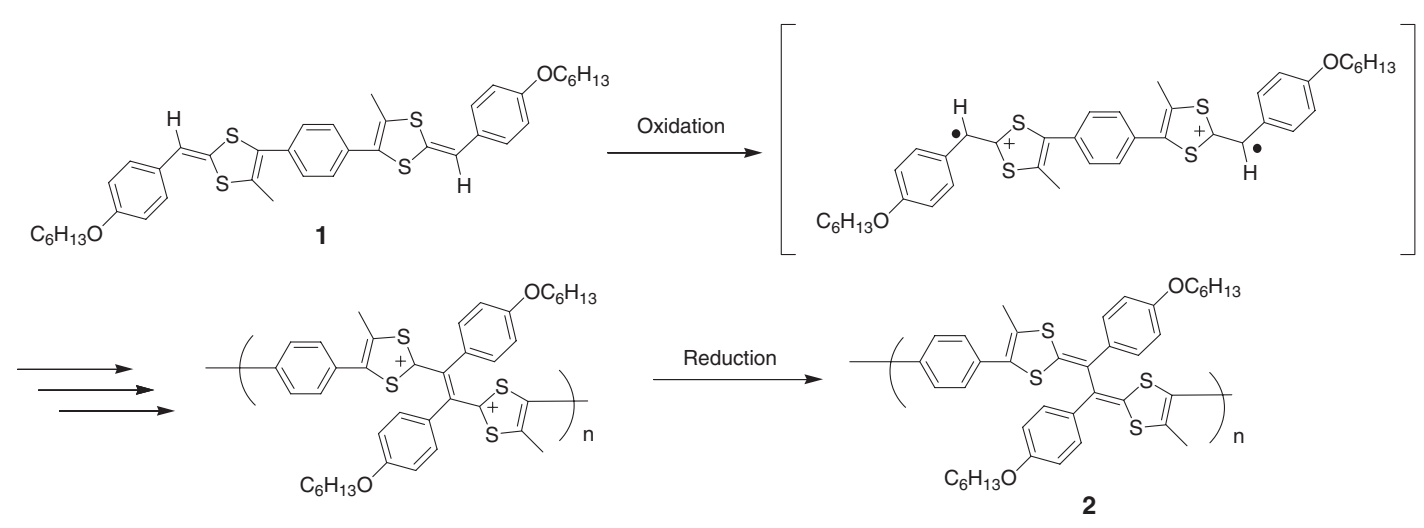

Scheme 2.

mixture. The organic phase was washed with water and evaporated. The polymeric product was solved in a small amount of $\mathrm{CHCl}_{3}$ and the solution was poured into a large amount of hexane. The resulting yellow precipitate was filtered $(41 \mathrm{mg}$, yield $72 \%)$ : ${ }^{1} \mathrm{H}$ NMR $\left(\mathrm{CDCl}_{3}, \mathrm{ppm}\right) \delta 7.41(\mathrm{~s}, 4 \mathrm{H}, \mathrm{Ar}-H), 7.34(\mathrm{~m}$, $4 \mathrm{H}, \mathrm{Ar}-H), 6.83(\mathrm{~m}, 4 \mathrm{H}, \mathrm{Ar}-H), 3.92\left(\mathrm{t}, 4 \mathrm{H}, \mathrm{OCH}_{2}\right)$, $2.02\left(\mathrm{~s}, 6 \mathrm{H}, \mathrm{CH}_{3}\right), 1.74\left(\mathrm{~m}, 4 \mathrm{H}, \mathrm{OCH}_{2} \mathrm{CH}_{2}\right), 1.42(\mathrm{~m}$, $\left.4 \mathrm{H}, \mathrm{OCH}_{2} \mathrm{CH}_{2} \mathrm{CH}_{2}\right), 1.32\left(\mathrm{~m}, 8 \mathrm{H}, \mathrm{OC}_{3} \mathrm{H}_{6} \mathrm{C}_{2} \mathrm{H}_{4}\right), 0.89$ (t, $\left.6 \mathrm{H}, \mathrm{OC}_{5} \mathrm{H}_{10} \mathrm{CH}_{3}\right) ;{ }^{13} \mathrm{C} \mathrm{NMR}\left(\mathrm{CDCl}_{3}, \mathrm{ppm}\right) \delta$ 157.4, 133.8, 132.3, 120.1, 129.1, 127.9, 125.6, 124.0, 123.3, 114.3, 67.9, 31.6, 29.2, 25.7, 22.6, 14.7, 14.0.

Typical oxidative polymerization by $\mathrm{FeCl}_{3}$ is as follows. To a stirred solution of $\mathbf{1}(11 \mathrm{mg}, 0.016 \mathrm{mmol})$ in $\mathrm{CHCl}_{3}(3 \mathrm{~mL})$, excess $\mathrm{FeCl}_{3}(30 \mathrm{mg}, 0.18 \mathrm{mmol})$ was added and the reaction mixture was stirred for $48 \mathrm{~h}$ at room temperature. The resulting mixture was poured into a large amount of methanol and black precipitate was filtered. The chemical reduction was carried out by addition of an aqueous solution of ammonia to the mixture. After $72 \mathrm{~h}$, the yellow precipitate was filtered and dried in vacuo. The polymeric product was solved in a small amount of $\mathrm{CHCl}_{3}$ and the solution was poured into a large amount of hexane. The resulting yellow precipitate was filtered $(5.2 \mathrm{mg}$, yield 47\%).

\section{RESULTS AND DISCUSSION}

Polymerization of bisdithiafulvenyldialkoxybenzenes was carried out by oxidation with iodine according to our previous works. ${ }^{28,29}$ After the chemical reduction of the doped polymers with sodium hydrogen sulfite, the neutral, vinylogous TTF-containing polymers were obtained. A novel type of bisdithiafulvene (bisDTF) (1) used as a monomer was designed, in which two DTFs were connected with a phenylene spacer on the 1,3-dithiole ring (Scheme 1). The synthesis began with 1,4-dipropionylbenzene (3), which was dichlorinated by lithium diisopropylamide (LDA) and $p$-toluenesulfonyl chloride. Then 1,4-bis(2-chloropropyl)benzene (4) was treated analogously according to the literature ${ }^{32}$ to prepare a phosphonate of DTF (9). The addition of $n$-butyllithium to 9 and following reaction with a 4-hexyloxybenzaldehyde generated bisDTF (1). Monomer 1 showed good solubility in common organic solvents such as $\mathrm{CHCl}_{3}$, $\mathrm{CH}_{2} \mathrm{Cl}_{2}$ and toluene due to the introduction of the alkoxy chain.

Oxidative polymerization of $\mathbf{1}$ was carried out as shown in Scheme 2 by the analogous procedure to the previous works. ${ }^{28,29}$ Treatment of $\mathbf{1}$ with iodine 
Table I. Results of polymerization

\begin{tabular}{ccccccc}
\hline entry & oxidant & solvent & $\begin{array}{c}\text { Polymerization } \\
\text { temperature }\left({ }^{\circ} \mathrm{C}\right)\end{array}$ & $M_{\mathrm{n}}{ }^{\mathrm{b}}$ & $M_{\mathrm{W}} / M_{\mathrm{n}}{ }^{\mathrm{b}}$ & yield (\%) \\
\hline 1 & $\mathrm{I}_{2}$ & $\mathrm{CH}_{2} \mathrm{Cl}_{2}$ & 25 & 3,900 & 2.0 & 40 \\
2 & $\mathrm{I}_{2}$ & $\mathrm{CH}_{2} \mathrm{Cl}_{2}$ & 50 & 3,800 & 1.7 & 68 \\
3 & $\mathrm{I}_{2}$ & $\mathrm{Toluene}_{4}$ & 25 & 5,400 & 2.3 & 73 \\
4 & $\mathrm{FeCl}_{3}$ & $\mathrm{CHCl}_{3}$ & 25 & 4,600 & 2.0 & 47 \\
\hline
\end{tabular}

${ }^{\mathrm{a}}$ Reaction time was $48 \mathrm{~h}$. ${ }^{\mathrm{b}}$ Determined by GPC analysis $\left(\mathrm{CHCl}_{3}\right.$, polystyrene standards).

formed a cation radical. Radical coupling reaction followed by dehydrogenation led to form a double bond in dication state, having $\mathrm{I}_{3}{ }^{-}$as a counter anion. Excess iodine and the counter anion were removed by the chemical reduction with an aqueous solution of sodium hydrogen sulfite. The crude polymer was purified by reprecipitation from a $\mathrm{CH}_{2} \mathrm{Cl}_{2}$ solution into a large amount of $n$-hexane. The obtained polymer was soluble in common organic solvents and was characterized and studied in detail. The number-average molecular weights $\left(M_{\mathrm{n}}\right)$ were determined by gel permeation chromatography (GPC) analysis in eluent $\mathrm{CHCl}_{3}$ calibrated with polystyrene standards. The results of polymerization under various conditions are summarized in Table I. The number-average molecular weight of the polymer in run 3 was estimated as 5,400 from GPC analysis (degree of polymerization was 7.9). During the polymerization of $\mathbf{1}$, the polymer product was precipitated in the reaction mixture. This might be a reason why DP is not so high. After reduction, the polymer was easily soluble in organic solvents.

The structure of the polymer was confirmed by ${ }^{1} \mathrm{H}$ and ${ }^{13} \mathrm{C}$ NMR spectroscopies measured in $\mathrm{CDCl}_{3}$ (Figure 1). In the ${ }^{1} \mathrm{H}$ NMR spectrum of the polymer, reasonable peaks corresponding to those of the monomers were seen with each peaks broadened and the benzylidene proton, observed at $6.41 \mathrm{ppm}$ in the spectrum of the monomer, disappeared. This result suggests the proceeding of dimerization reaction of the dithiafulvene and the incorporation of vinylogous TTF unit in the main chain of the polymer. In the ${ }^{13} \mathrm{C}$ NMR spectrum of the polymer, the peak of the benzylidene was shifted to lower magnetic field after the polymerization due to the formation of the vinylogous TTF unit. MALDI-TOF-MS analysis for the polymer also provided the evidence of the proceeding of the polymerization. The peak intervals were corresponded to the molecular weight of the repeating unit. Although the ${ }^{1} \mathrm{H}$ NMR spectrum of the polymer shows a small peak at $6.41 \mathrm{pp}$ assignable the terminal proton, the peak intensity was too small for the DP of the polymer. This may indicate the formation of cyclic polymer.

The UV-visible absorption spectra of the polymer and the monomer were measured in $\mathrm{CHCl}_{3}$. The absorption maximum derived from the $\pi-\pi^{*}$ transition
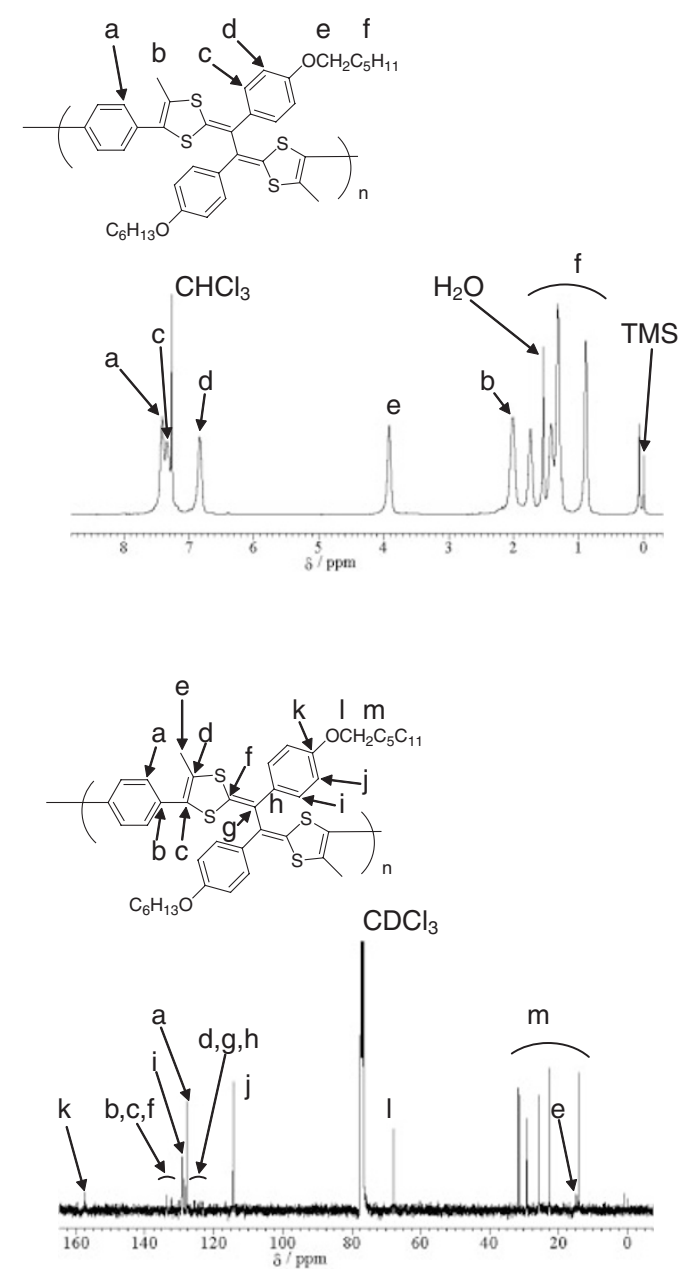

Figure 1. ${ }^{1} \mathrm{H}$ and ${ }^{13} \mathrm{C}$ NMR spectra of 2 in $\mathrm{CDCl}_{3}$.

of the monomer was seen at $347 \mathrm{~nm}$. In the spectrum of the polymer, the absorption maximum was slightly red-shifted from that of the monomer. Extension of the $\pi$-conjugation seems to be prevented by the steric hindrance of the methyl group on the dithiafulvene and the phenylene moieties.

The electrochemical behavior of the polymer was studied by cyclic voltammetry (Figure 2). The oxidation peak potentials of the polymer were observed at lower potential $(115 \mathrm{mV}$ and $215 \mathrm{mV})$ compared to that of the monomer $(400 \mathrm{mV})$, indicating the formation of the vinylogous TTF unit in the polymer chain by the oxidative polymerization. The potential differ- 

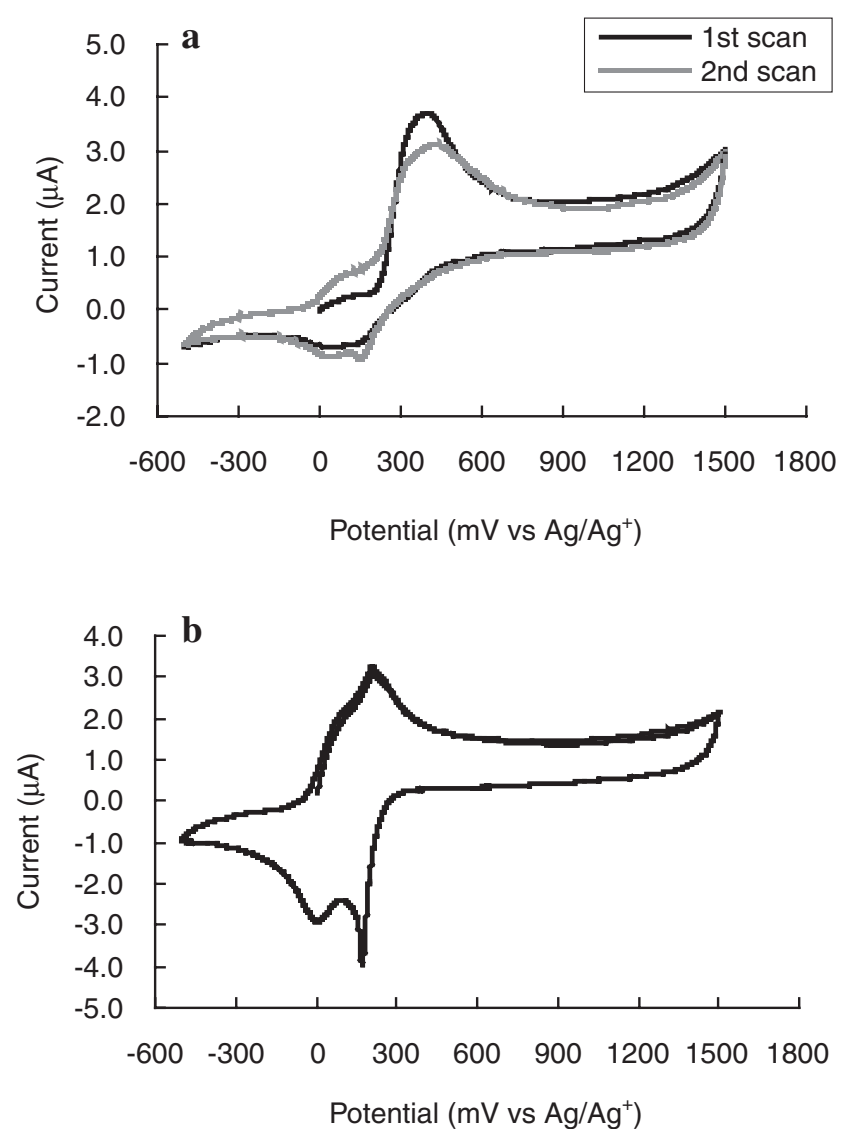

Figure 2. Cyclic voltammograms of (a) 1 and (b) 2 in $\mathrm{CH}_{2} \mathrm{Cl}_{2}$ solutions of $0.1 \mathrm{M}\left[\mathrm{NBu}_{4}\right] \mathrm{PF}_{6}$ at $100 \mathrm{mV} / \mathrm{s}$.

ence between the oxidation peak and the corresponding reduction peak of vinylogous TTF moiety $\left(\Delta \mathrm{E}_{\mathrm{p}}=\right.$ $\mathrm{E}_{\mathrm{p}}{ }^{\mathrm{a}}-\mathrm{E}_{\mathrm{p}}{ }^{\mathrm{c}}$ ) was estimated as $110 \mathrm{mV}$ for first oxidation and $52 \mathrm{mV}$ for second oxidation. An apparent broad oxidation peak suggested the intramolecular interaction of the vinylogous TTF units in the polymer. The second scan of the polymer solution showed the same behavior with the first scan, that is the reaction was reversible.

In the voltammograms of the monomer as shown in Figure $2 \mathrm{a}$, the peak at $0.40 \mathrm{~V}$ was decreased in the second scan and new peaks appeared at the lower potential area (corresponding to the oxidation potential of the vinylogous TTF). Under this condition, the oxidative dimerization (polymerization) occurred during the measurement. Electrochemical polymerization of the monomer was investigated by repeating $\mathrm{CV}$ analysis (Figure 3). As the cycles proceeded, the oxidation peak derived from the dithiafulvene was decreased and the new oxidation peaks increased at the area derived from the vinylogous TTF. After 50 cycles, the reaction solution was evaporated and the precipitated electrolyte by addition of toluene was filtered. From the GPC analysis of this crude product, the polymeric peak (peak top molecular weight $\sim 5000$ ) and the monomeric peak were observed. Ox-

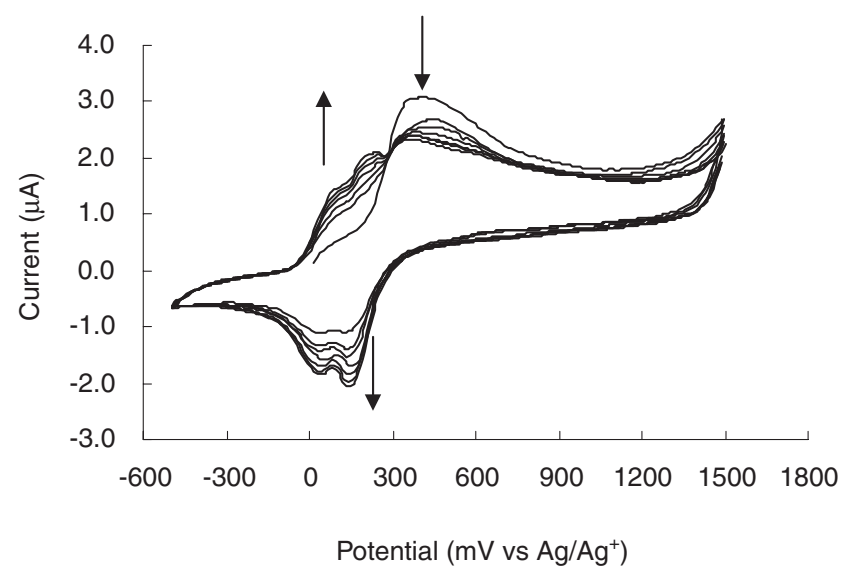

Figure 3. Cyclic voltammograms of $\mathbf{1}$ in a $\mathrm{CH}_{2} \mathrm{Cl}_{2}$ solution of $0.1 \mathrm{M}\left[\mathrm{NBu}_{4}\right] \mathrm{PF}_{6}$ at $100 \mathrm{mV} / \mathrm{s} .1 \mathrm{st}, 3 \mathrm{rd}, 10 \mathrm{th}, 20 \mathrm{th}, 30$ th, 40th, and 50th cycles were recorded.

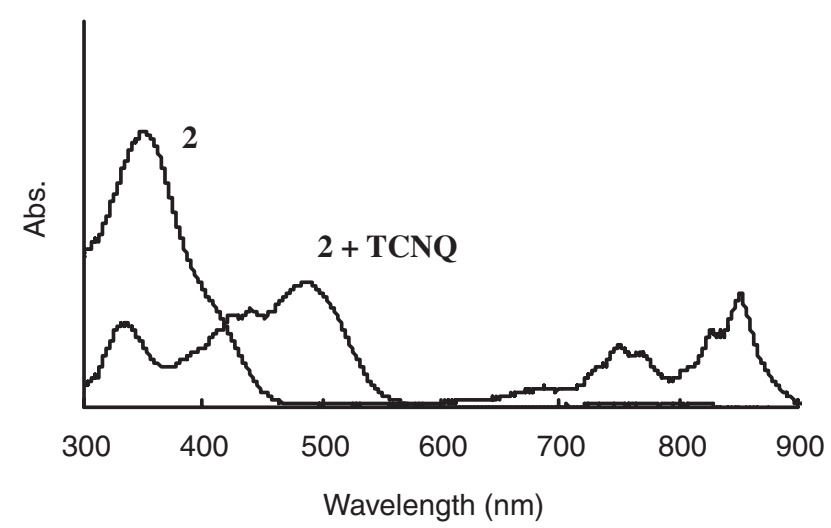

Figure 4. UV-vis spectra of 2 and the CT complex composed of 2 and TCNQ in DMSO.

idative polymerization of the monomer was successful by not only chemical oxidation but also electrochemical oxidation.

In our previous work, ${ }^{28,29}$ the vinylogous TTF-containing polymers, which have dithiole-rings in the side chain, were prepared by oxidative polymerization procedure. These polymers formed the charge transfer (CT) complexes with TCNQ in DMSO and $\mathrm{CHCl}_{3}$. From the UV-vis spectrum of the CT complexes, the vinylogous TTF units were found to be the cation radical states. The present polymer also formed a stable CT complex with TCNQ in DMSO. Figure 4 shows the UV-vis spectrum of the CT complex after an excess amount of TCNQ was added to a DMSO solution of the polymer. The absorption for the anion radical of TCNQ was observed at $600-900 \mathrm{~nm}$ and $400 \mathrm{~nm}$. Another specific absorption at $475 \mathrm{~nm}$ was assignable to the dication of the vinylogous TTF unit according to our previous result. ${ }^{28}$ The dication formation of the present polymer is reasonable due to the reduced coulombic repulsion in the framework of vinylogous TTF and was also supported by the result of $\mathrm{CV}$ analysis. 


\section{CONCLUSIONS}

We succeeded in preparing the novel electrondonating polymer containing vinylogous TTF unit in the main chain by oxidative polymerization of bisDTF 1. The polymer was soluble in common organic solvents and well-characterized. The electron-delocalization throughout the polymer chain was not confirmed by the UV-vis spectra. The electrochemical polymerization was also succeeded by the $\mathrm{CV}$ measurement in solution. The vinylogous TTF unit in the polymer easily formed the dication by electrochemical method and by the addition of the electron acceptor because of the reduced coulombic repulsion in the dication species. This highly charged polymer can be applied to a new kind of polyelectrolyte.

Acknowledgment. We would like to thank Prof. Mitsuo Sawamoto at Kyoto University for the MALDI-TOF-MS analysis.

\section{REFERENCES}

1. J. H. Perlstein, Angew. Chem., Int. Ed., 15, 519 (1977).

2. A. M. Kini, U. Geiser, H. H. Wang, K. D. Carlson, J. M. Williams, W. K. Kwok, K. G. Vandevoot, J. E. Thompson, D. L. Stupka, D. Jung, and M. H. Whangbo, Inorg. Chem., 29, 2555 (1990).

3. T. Komatsu, T. Nakamura, N. Matsukawa, H. Yamochi, G. Saito, H. Ito, T. Ishiguro, M. Kusunoki, and K. Sakaguchi, Solid State Commun., 80, 101 (1992).

4. Z. Yoshida and T. Sugimoto, Angew. Chem., Int. Ed., 27, 1573 (1988).

5. T. Sugano, T. Fukasawa, and M. Kinoshita, Synth. Met., 41-43, 3281 (1991).

6. R. Kumai, A. Izuoka, and T. Sugawara, Mol. Cryst. Liq. Cryst., 232, 151 (1993).

7. J. L. Segura and N. Martín, Angew. Chem., Int. Ed., 40, 1372 (2001).

8. M. B. Nielsen, C. Lomholt, and J. Becher, Chem. Soc. Rev., 29, 153 (2000).

9. T. Shimizu and T. Yamamoto, Chem. Commun., 1999, 515 (1999).

10. J. E. Mulvaney and D. M. Chang, Macromolecules, 13, 240
(1980).

11. S. Frenzel, S. Arndt, R. M. Gregorious, and K. Müllen, J. Mater. Chem., 5, 1529 (1995).

12. C. U. Pittman Jr., M. Ueda, and Y. F. Liang, J. Org. Chem., 44, 3639 (1979).

13. Y. Ueno, Y. Masuyama, and M. Okawara, Chem. Lett., 4, 603 (1975).

14. W. R. Hertler, J. Org. Chem., 41, 1412 (1976).

15. T. Yamamoto and T. Shimizu, J. Mater. Chem., 7, 1967 (1997).

16. K. Naka, T. Uemura, and Y. Chujo, Macromolecules, 31, 7570 (1998).

17. K. Naka, T. Uemura, and Y. Chujo, Macromolecules, 33, 4733 (2000).

18. K. Naka, T. Uemura, and Y. Chujo, Macromolecules, 33, 6965 (2000).

19. H. Müller, F. Salhi, and B. Divisia-Blohorn, Tetrahedron Lett., 38, 3215 (1997).

20. H. Müller, F. Salhi, B. Divisia-Blohorn, F. Genoud, T. Narayanan, M. Lorenzen, and C. Ferrero, Chem. Commun., 1999, 1407 (1999).

21. K. Naka, T. Uemura, and Y. Chujo, Polym. J., 32, 435 (2000).

22. K. Naka, T. Uemura, and Y. Chujo, Macromolecules, 33, 4733 (2000).

23. D. Lorcy, L. Mattiello, C. Periel, and J. Rault-Berthelot, J. Electroanal. Chem., 530, 33 (2002).

24. M. Fourmigué, I. Johannsen, K. Boubekeur, C. Nelson, and P. Batail, J. Am. Chem. Soc., 115, 3752 (1993).

25. S. González, N. Martín, L. Sánchez, J. L. Segura, and C. Seoane, J. Org. Chem., 64, 3498 (1999).

26. J. Roncali, J. Mater. Chem., 7, 2307 (1997).

27. R. Berridge, P. J. Skabara, R. Andreu, J. Garín, J. Orduna, and M. Torra, Tetrahedron Lett., 46, 7871 (2005).

28. K. Naka, S. Inagi, and Y. Chujo, J. Polym. Sci., Part A: Polym. Chem., 43, 4600 (2005).

29. K. Naka, S. Inagi, Y. Murachi, and Y. Chujo, J. Polym. Sci., Part A: Polym. Chem., 44, 2027 (2006).

30. D. Lorcy, R. Carlier, A. Robert, A. Tallec, P. Le Maguerès, and L. Ouahab, J. Org. Chem., 60, 2443 (1995).

31. P. Hapiot, D. Lorcy, A. Tallec, R. Carlier, and A. Robert, J. Phys. Chem., 100, 14823 (1996).

32. J. Rault-Berthelot and C. Rozé, Synth. Met., 93, 97 (1998).

33. P. Wei, D. Wang and Z. Wu, Macromol. Rapid Commun., 22, 1143 (2001).

34. K. M. Brummond and K. D. Gesenberg, Tetrahedron Lett., 40, 2231 (1999). 